https://helda.helsinki.fi

Changes in expression and honesty of sexual signalling over the reproductive lifetime of sticklebacks

\title{
Candolin, Ulrika
}

Royal Society of London

2000

Proceedings of the Royal Society of London Series B 267 (1460) 2425-2430

http://hdl.handle.net/1975/147

Downloaded from Helda, University of Helsinki institutional repository.

This is an electronic reprint of the original article.

This reprint may differ from the original in pagination and typographic detail.

Please cite the original version. 


\title{
Changes in expression and honesty of sexual signalling over the reproductive lifetime of sticklebacks
}

\author{
Ulrika Candolin*
}

Department of Biology, Section of Ecology, University of Turku, FIN-20014 Turku, Finland

\begin{abstract}
Fitness costs of signalling are essential in order for reliable sexual signalling to prevail when the interests of the sexes conflict. This means that signalling can be subjected to a life history trade-off between present and future signalling effort. Here, I show that three-spined stickleback males (Gasterosteus aculeatus), who have a single breeding season during which they breed repeatedly, change their red nuptial coloration over the season depending on their body size at the start of breeding. Large males that completed several breeding cycles increased their red coloration over the season, whereas small males, who completed only a few cycles, did not. The increase in coloration was accompanied by an increase in parental success when males were energy constrained, but not when they had access to an unlimited food supply. Red coloration was thus an honest signal of male parental ability despite changes in signal expression when both signalling and parental care were costly and the investments in them changed simultaneously over the reproductive lifetime. However, the honesty of the signal varied over a lifetime. At the penultimate cycle, bright males cannibalized some of their eggs, probably to increase survival to the last cycle, whereas males cared for their offspring independent of coloration at the ultimate cycle.
\end{abstract}

Keywords: sexual signalling; indicator mechanism; parental investment; filial cannibalism; nuptial coloration; three-spined stickleback

\section{INTRODUCTION}

Honest sexual signalling requires fitness costs in order for the optimal balancing of costs and benefits to result in a positive correlation between mate quality and signal expression (Zahavi 1975; Getty 1998). However, the cost of signalling in terms of reduced survival and future reproductive success may decrease with decreasing future reproductive opportunities in species that breed repeatedly. This may increase the investment in present signalling as a terminal effort and could lead to dishonest signalling (fig. $1 b$ in Kokko 1998). Whether the signalling system is then honest on average and stable depends on the frequency of cheaters (Johnstone \& Grafen 1993).

An effect of reduced life-span expectancy on signalling effort has been detected in Drosophila and in three-spined sticklebacks (Gasterosteus aculeatus). In Drosophila, parasitized males with a reduced longevity increase their courtship activity (Polak \& Starmer 1998), whereas fooddeprived stickleback males in poor condition develop more red carotenoid-based nuptial coloration than well-fed males (Hosking 1996; Baube 1997; Candolin 1999a). However, whether an increased signalling effort due to reduced longevity increases dishonesty is not known. In sticklebacks, an important measure of male quality is the parental ability of the male, as males care for the offspring alone for approximately two weeks. An increased signalling effort could be accompanied by an increased paternal effort so that the signal remains honest.

I investigated whether (i) red colour expression of three-spined sticklebacks changes over the breeding

\footnotetext{
*Author and address for correspondence: School of Biological Sciences, University of East Anglia, Norwich NR4 7TJ, UK (u.candolin@uea.ac.uk).
}

season when future reproductive opportunities decrease, and (ii) whether this influences signal reliability in relation to male parental ability. Future reproductive opportunities decrease with the progress of the season as sticklebacks in the present population have a single breeding season during which they breed repeatedly. This should decrease the cost of reproduction in terms of loss of future reproductive opportunities towards the end of the breeding season. The carotenoid-based colour is costly by increasing the risk of predation (Moodie 1972; Whoriskey \& FitzGerald 1985), by reducing immunocompetence (Milinski \& Bakker 1990; Lozano 1994; Wedekind et al. 1998) and by depleting energy and nutrient stores (Frischknecht 1993). The benefit of signalling was kept constant by allowing each male to mate with only one female per breeding cycle. In order to investigate whether energy constraints influence the trade-off between present and future reproduction and, thus, signal quality and reliability, I raised males on high and low food rations. Reproductive activities are energetically costly and low food rations might increase the benefits of partial filial cannibalism as a way of increasing lifetime reproductive success by increasing the number of breeding cycles or the amount of resources available for signalling at each cycle (Rohwer 1978; Sargent 1992). However, male filial cannibalism decreases the reproductive success of the female and an honest signalling system should reveal the risk that a male will cannibalize the eggs he receives.

\section{METHODS}

I collected three-spined sticklebacks with traps from the littoral of the Baltic Sea near Tvärminne Zoological Station in southern Finland. The fishes were collected before the start of 
the breeding season (end of April) in 1998. Sexes were housed in separate holding aquaria for five days at $18{ }^{\circ} \mathrm{C}$ under natural lighting conditions. Fishes were fed daily on dried Tubifex worms and frozen chironomid larvae. Breeding behaviour was discouraged by the lack of suitable nesting material.

I randomly selected 20 males with blue eyes (which indicates sexual maturation), determined their wet weight and body length and placed them singly into experimental flow-through aquaria $(50 \mathrm{~cm}$ long $\times 40 \mathrm{~cm}$ wide $\times 30 \mathrm{~cm}$ high). The aquaria were exposed to the same conditions as the holding aquaria. I kept the temperature at $18{ }^{\circ} \mathrm{C}$ instead of increasing it over the season as the water temperature in the field fluctuates due to occasional upwellings of cold water. Each aquarium contained a nesting dish filled with $1 \mathrm{~cm}$ of sand, an artificial plant and filamentous green algae (Cladophora) as nesting material. White curtains with small viewing holes reduced external disturbance. I randomly assigned the males to two feeding treatments: half of the males (mean standardized body length \pm s.e. $=56.4$ $\pm 0.8 \mathrm{~mm}$ ) were fed in excess daily on chironomid larvae (high food ration), whereas the others (body length $55.3 \pm 0.6 \mathrm{~mm}$ ) were fed only two large chironomid larvae a day (low food ration). In order to stimulate nest building, I showed each male a gravid female enclosed in a Plexiglass cylinder for 5 min twice a day. Most males built a nest within one to three days.

When a male had completed nest building and developed red nuptial coloration and entered the courtship phase, I measured his nuptial colour. I allowed the male to court a female enclosed in a Plexiglass cylinder and then photographed his left lateral side under standardized conditions in a box containing a digital camera (see Candolin (1999b) for details). I used a tristimulus system constructed to fit the human eye since the colour vision of sticklebacks does not differ greatly from that of humans (reviewed by Frischknecht 1993; McKinnon 1995). I determined the extent and quality of the red coloration from the digital images using image analysing software (MCID-M4, Imaging Research, Inc., St Catherines, Ontario, Canada) (see Candolin $(1999 b)$ for details). The size of the male's red area is given as a percentage of his total lateral area.

One hour after photography, when the male had resumed normal activities, I put a gravid female into the aquarium and allowed her to spawn in the male's nest. If a female did not spawn within $1 \mathrm{~h}$, I replaced her with a new female. Most females spawned and the mean number of females presented to a male per breeding cycle (mean number of females \pm s.e. $=1.08 \pm 0.04)$ did not differ between food rations (MannWhitney $U$-test, $U=55, \mathcal{N}_{1}=\mathcal{N}_{2}=10$ and $p=0.6$ ) or change over the succession of breeding cycles (Kruskal-Wallis test, $H=2.3$ and $p=0.8$. The female was removed immediately after spawning. I determined the amount of eggs spawned by both recording female wet weight before and after spawning and by weighing the eggs $3-4 \mathrm{~h}$ after spawning when the egg mass had hardened (see Candolin (2000) for details). The two measures of egg mass were highly correlated $(r=0.99, n=67$ and $p<0.001)$, and I used the latter direct measure of egg quantity in the analyses. The size of the egg clutches did not change over the breeding cycles (Kruskal-Wallis test, $H=2.4$ and $p=0.6$ ).

Since nuptial coloration may change after mating, I measured red coloration one day after spawning using the same methods as described above. Only the results for red coloration before mating are given since nuptial coloration did not change. After colour measurement, I left the male to care for the eggs. I determined the percentage of the eggs that had reached the hatching stage eight days later by removing dead or undeveloped eggs and weighing the remaining eggs as described above. The eggs would have hatched on the ninth or tenth days and the number of developed, healthy eggs present at day 8 has been found to agree with the number of eggs actually hatching when a male is allowed to continue to care for the eggs until hatching $\left(r^{2}=0.996, b=0.943, F_{1,14}=3102\right.$ and $\left.p<0.000\right)$. Any changes in the weight of an egg were the same over replicates and did not confound the results. After weighing, I returned the eggs to the male and allowed him to raise the offspring to independence in order to complete the parental phase. I then weighed the male to determine the amount of wet weight lost during the breeding cycle and allowed him to begin a new breeding cycle. I cleaned the aquarium from algae to facilitate further observations, exchanged the water to remove any hatched offspring and provided the male with new fresh nesting materials. I submitted the male to the same procedures as during the first breeding cycle. All males were allowed to enter and complete new breeding cycles until they died or stopped breeding because the breeding season had ended.

Since males differed in the number of breeding cycles that they completed, I investigated the change in trait expression from the first to the last cycle with repeated-measures ANCOVA with feeding treatment as a factor and number of completed breeding cycles and body weight and standardized length at the start of breeding as covariates. A covariate was excluded from the model when the interaction with time was not significant and the exclusion did not influence the significance of the study variables. The values reported are means \pm s.e.

\section{RESULTS}

\section{(a) Red coloration}

The percentage area of red increased from the first to the last breeding cycle independent of food rations but depending on the weight of the male at the start of the season: heavier males increased their red areas more than lighter males (table 1 and figures 1 and 2). Heavier males also completed more cycles $\left(r^{2}=0.24, \quad F_{1,18}=5.67\right.$ and $p=0.029)$ and a marginally significant interaction was found between date and number of cycles when the model was run with only the number of cycles as a covariate $\left(F_{1,17}=3.57\right.$ and $\left.p=0.076\right)$. Red area did not depend on male weight at the first cycle $\left(r^{2}=0.06, F_{1,18}=1.14\right.$ and $p=0.30)$. The increase in red area levelled off after the first three cycles for males that completed more cycles (figure 1). This was demonstrated by a significant quadratic within-subject contrast term in repeatedmeasures ANOVA for the first four cycles when males on high and low rations were pooled $\left(F_{1,6}=6.5\right.$ and $p=0.043)$ whereas only a significant linear contrast term was attained for the first three cycles (linear term $F_{1,12}=55.2$ and $p<0.001$ and quadratic term $F_{1,12}=1.18$ and $p=0.20)$.

Males on low rations had larger red areas than males on high rations but their areas tended to be less saturated and less bright in colour (table 1). However, colour quality changed from the first to the last breeding cycle depending on food rations (table 1): males on low rations developed more saturated $(0.19 \pm 0.01-0.20 \pm 0.01)$ and brighter red areas $(0.55 \pm 0.01-0.53 \pm 0.01$ ) (a low value of intensity indicates a brightly coloured fish as colour pigments reduce the amount of light reflected), whereas males on high rations tended to have less saturated 
Table 1. Repeated-measures ANCOVA/ANOVA of red coloration at the first and the last breeding cycle (date) with food rations as a factor and male weight at the start of breeding as a covariate

(The degrees of freedom were 1,17 for red area and 1,18 for colour qualities.)

\begin{tabular}{|c|c|c|c|c|c|c|c|c|c|c|}
\hline \multirow[b]{3}{*}{ source } & \multicolumn{4}{|c|}{ difference between individuals } & \multicolumn{6}{|c|}{ difference within individuals } \\
\hline & \multicolumn{2}{|c|}{ food rations } & \multicolumn{2}{|c|}{ weight } & \multicolumn{2}{|c|}{ date } & \multicolumn{2}{|c|}{ date $\times$ food rations } & \multicolumn{2}{|c|}{ date $\times$ weight } \\
\hline & $F$ & $p$ & $F$ & $p$ & $F$ & $p$ & $F$ & $p$ & $F$ & $p$ \\
\hline \multicolumn{11}{|l|}{ red coloration } \\
\hline hue & 1.13 & 0.300 & - & - & 0.23 & 0.64 & 0.16 & 0.700 & - & - \\
\hline saturation & 4.40 & 0.050 & - & - & 0.01 & 0.91 & 4.95 & 0.039 & - & - \\
\hline intensity & 3.48 & 0.080 & - & - & 0.18 & 0.68 & 3.38 & 0.080 & - & - \\
\hline
\end{tabular}
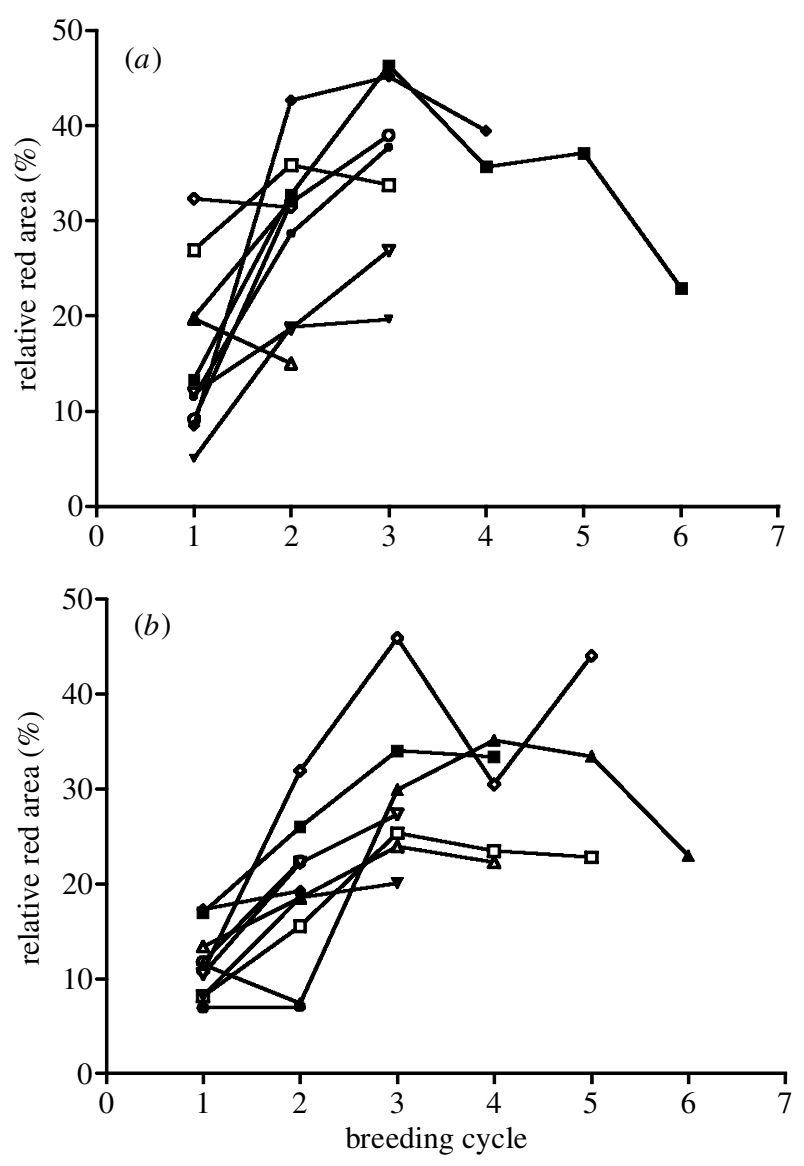

Figure 1. Red area at each breeding cycle for males on (a) low rations and $(b)$ high rations.

$(0.21 \pm 0.00-0.20 \pm 0.01)$ and less bright areas $(0.49 \pm 0.02-0.52 \pm 0.03)$. The colour quality of the red areas thus became more similar for males on low and high rations at the last cycle.

\section{(b) Hatching success}

The increase in red area from the first to the last cycle (percentage area at last cycle - percentage area at first cycle) correlated positively with an increase in hatching success (percentage at last cycle - percentage at first cycle) (Pearson's product-moment correlation, $r=0.46$, $n=20$ and $p=0.041$ ) (figure $3 a$ ). Males often cannibalized the whole brood at the first cycle (figure $3 b$ ) whereas

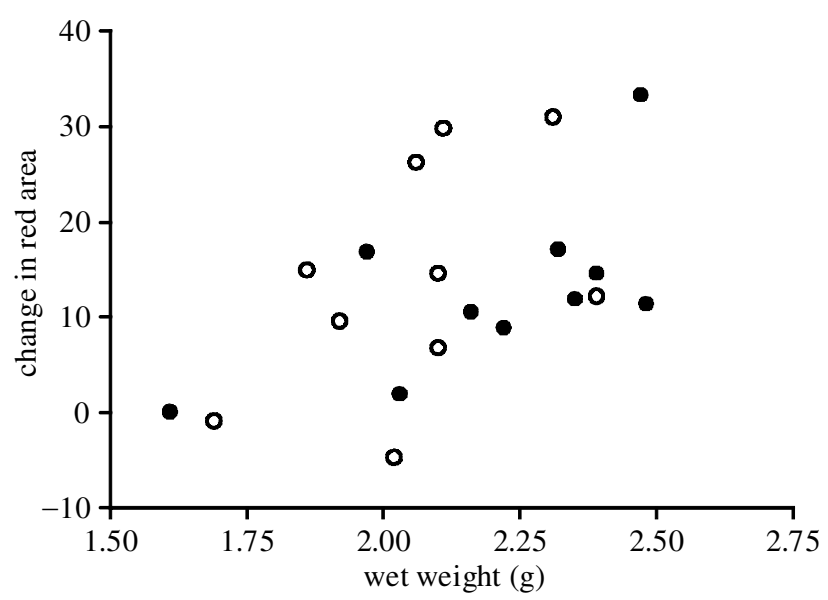

Figure 2. Relationship between male wet weight at the start of breeding and the change in red area from the first to the last cycle. Open circles are males on low rations and filled circles are males on high rations.

partial cannibalism mainly occurred later (figure $3 c, d$ ). However, the correlation was only significant for males on low rations $(r=0.85, n=10$ and $p=0.002)$ and not for males on high rations $(r=0.18, n=10$ and $p=0.62)$ (the two correlation coefficients are significantly different: $Z=2.69$ and $p<0.01$ ) (Zar 1996). This is due to males on high rations often having a high hatching success despite a small red area. On average, males on low rations tended to have a lower hatching success than males on high rations (percentage of all eggs received during the season that hatched, low rations $66.1 \pm 5.7 \%$ and high rations $79.2 \pm 4.9 \%) \quad(t 18=1.74$ and $p=0.099)$. Low hatching success was mainly due to cannibalism as very few eggs were dead or unfertilized, although the state of the eggs when eaten was not known.

The honesty of the signal varied over the breeding season. Red area indicated male parental ability at the first cycle (Spearman's rank correlation, $r_{\mathrm{s}}=0.59, n=20$ and $p=0.006$ ) (figure $3 b$ ) but not at the penultimate cycle $\left(r_{\mathrm{s}}=0.02, n=20\right.$ and $p=0.93$ ) (figure $3 c$ ) or at the last cycle $\left(r_{\mathrm{s}}=0.36, n=20\right.$ and $p=0.12$ ) (figure $\left.3 d\right)$. However, the correlation coefficients were not statistically different (difference between the first cycle and penultimate cycle $Z=1.92$ and $p=0.056$ and between the first and last cycle $Z=1.07$ and $p=0.3$ ). At the penultimate 

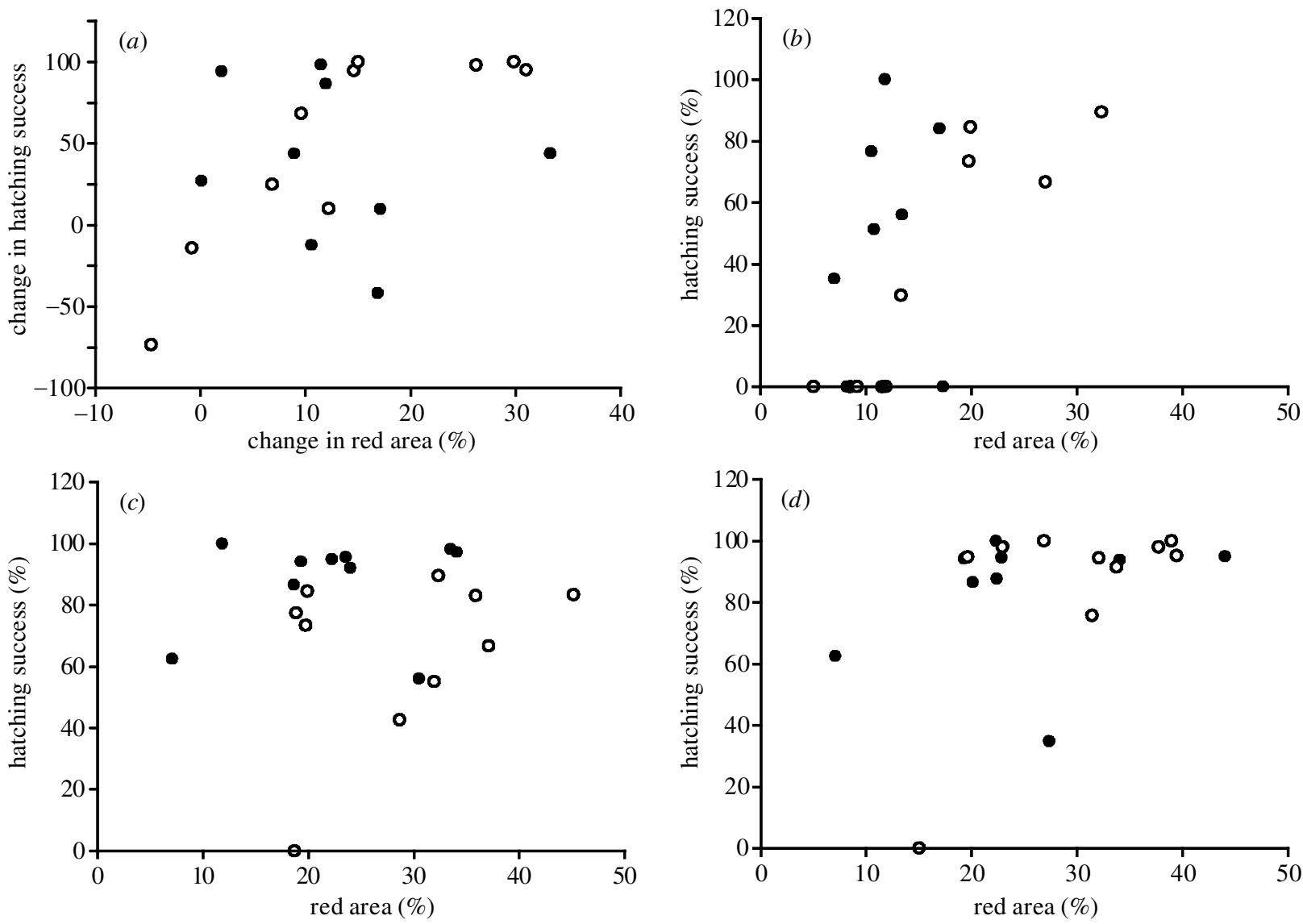

Figure 3. Relationship between change in $(a)$ hatching success and change in red area from the first to the last cycle, $(b)$ hatching success and red area at the first cycle, $(c)$ hatching success and red area at the penultimate cycle and $(d)$ hatching success and red area at the last cycle. Open circles, males on low food rations; filled circles, males on high rations.

cycle, males developed large red areas but often cannibalized their eggs. At the last cycle males usually raised most of their offspring to the hatching stage independent of their colour expression. Again, the correlation at the first cycle was only significant for males on low rations $\left(r_{\mathrm{s}}=0.90, n=10\right.$ and $\left.p<0.001\right)$ and not for males on high rations $\left(r_{\mathrm{s}}=0.30, n=10\right.$ and n.s.). These correlation coefficients were significantly different $(Z=2.17$ and $p=0.030)$.

Food rations influenced male weight. Males on low rations lost weight (from $2.06 \pm 0.06 \mathrm{~g}$ to $1.56 \pm 0.08 \mathrm{~g}$ ) whereas males on high rations gained weight (from $2.20 \pm 0.08 \mathrm{~g} \quad$ to $2.43 \pm 0.13 \mathrm{~g}$ ) (repeated-measures ANOVA, food ration $F_{1,18}=18.45$ and $p<0.001$ and date food ration $F_{1,18}=36.28$ and $p<0.001$ ).

\section{DISCUSSION}

Three-spined stickleback males changed the extent of their red nuptial coloration over the breeding season depending on their body size at the start of breeding. Large males that were able to complete several cycles increased their red coloration, whereas small males that only completed a few cycles did not. This suggests that the signalling tactic of the males depended on their condition and future reproductive opportunities. Small males appear to have invested heavily in signalling already at the first cycle and then not increased their coloration at the few subsequent cycles that they completed. Large males, on the other hand, who were able to complete more cycles, initially developed red areas of the same size as small males, but then gradually increased their signal expression over the breeding season.

The dependence of signalling tactic on condition and expected future reproductive opportunities was probably due to a trade-off between present and future signalling effort with males adjusting their signalling effort to changes in the costs and, perhaps, benefits of signalling. The costs of signalling in terms of loss of future reproductive opportunities through death or the depletion of resources should decrease when the opportunities for additional reproductive events decrease. This may have induced males to increase their investment in present reproduction as a terminal effort towards the end of their lifetime as suggested by other studies (Polak \& Starmer 1998; Candolin 1999a). The benefits of signalling, on the other hand, might increase over the season in the wild if the dependence of mating success on signal quality increases due to increased competition for mates through, for example, an increased male bias in the operational sex ratio (Emlen \& Oring 1977). In this case, the increased signalling effort would need to be a genetically set adaptation to increased benefits under natural conditions, as the benefits did not change in the present aquarium study.

An alternative possibility is that the increase in red area was just a consequence of the accumulation of carotenoids. However, this is unlikely as the increase in red 
was independent of food rations and males on low rations developed more saturated, bright red areas towards the end of the season whereas males on high rations did not.

Interestingly, the increase in red was accompanied by an increase in parental success when males were food restricted. Parental care is energetically costly (Stanley 1983; Chellappa et al. 1989; FitzGerald et al. 1989) and probably also subjected to a trade-off between present and future parental investment. At the start of the breeding season, the care of one single clutch may incur larger costs than benefits in terms of time and energy and males may cannibalize the whole clutch as an investment in future reproduction in order to acquire energy and carotenoids for starting a new, more rewarding cycle. Later in the season, partial cannibalism may predominate instead as an investment in present reproduction in order to ensure that at least some offspring reach independence (Rohwer 1978; Sargent 1992). The correlation between red area and hatching success would then be due to both being subjected to a trade-off between present and future reproduction and males changing their investment in them simultaneously. These results point to the importance of costs in the maintenance of honest sexual signalling, as signalling did not reflect male parental ability when males had access to an unlimited food source. They suggest that food constraints may have been important in the evolution of the signalling system in nature.

Another possibility is that the red area correlated with the ability of the male to fertilize the eggs and that dull males cannibalized a large proportion of the eggs because they were unfertilized. However, this does not explain the difference between males on low and high food rations in the correlation between red area and hatching success and is probably not the whole explanation.

The relationship between red area and hatching success at each cycle varied over the breeding season. While red area reflected hatching success at the first cycle, several bright males on low food rations cannibalized a large proportion of the eggs at the penultimate cycle, whereas males cared for their offspring independent of their coloration at the ultimate cycle. Males at the penultimate cycle were probably trading some present reproduction in favour of a last reproductive opportunity in order to increase their lifetime reproductive success. An increased investment in signalling is consequently not always followed by an increased parental effort. However, the dishonesty may not distort the stability of the signalling system if the frequency of cheaters is low (Johnstone \& Grafen 1993). Since the increase in red area on average correlated with an increase in parental effort, some cheating may be allowed in the stickleback system.

The reduction in signal intensity at the last breeding cycles for the males that completed the most cycles could either be due to the exhaustion of resources such as carotenoids or to changes in levels of hormones due to changes in daylight as the last cycles took place at the end of July (Baggerman 1980; Borg 1982; Guderley 1994). Interestingly, no males died when caring for their offspring. The costs of entering new breeding cycles, such as the costs of building a nest (Stanley \& Wootton 1986) and developing red coloration, may have prevented males that would not survive the parental phase from entering new cycles.

In conclusion, this study showed that signal intensity changes over the reproductive lifetime of sticklebacks depending on their condition and expected future reproductive opportunities. An increase in red area is accompanied by an increased parental effort when both signalling and parental care are costly and probably subjected to a trade-off between present and future effort. However, investments in signalling and parental care do not always coincide and some dishonesty can occur.

I thank Tom Getty, Hanna Kokko, Janne Kotiaho, Kai Lindström and an anonymous referee for discussions and/or comments on the paper. This study was supported by the Graduate School of Evolutionary Ecology and the Foundation for Female Scientists in Finland.

\section{REFERENCES}

Baggerman, B. 1980 Photopheriodic and endogenous control of the annual reproductive cycle in teleost fishes. In Environmental physiology of fishes (ed. M. A. Ali), pp. 533-567. New York: Plenum.

Baube, C. L. 1997 Manipulations of signalling environment affect male competitive success in three-spined sticklebacks. Anim. Behau 53, 819-833.

Borg, B. 1982 Seasonal effects of photoperiod and temperature on spermatogenesis and male secondary sexual characteristics in the three-spined stickleback, Gasterosteus aculeatus L. Can. $\mathcal{F}$. Zool. 60, 3377-3386.

Candolin, U. 1999 $a$ The relationship between signal quality and physical condition: is sexual signalling honest in the threespined stickleback? Anim. Behav. 58, 1261-1267.

Candolin, U. 1999b Male-male competition facilitates female choice in sticklebacks. Proc. R. Soc. Lond. B 266, 785-789.

Candolin, U. 2000 Increased signalling effort when survival prospects decrease: male-male competiton ensures honesty. Anim. Behau 60, 417-422.

Chellappa, S., Huntingford, F. A., Strang, R. H. C. \& Thomson, R. Y. 1989 Annual variation in energy reserves in male three-spined stickleback, Gasterosteus auleatus L. (Pisces, Gasterosteidae). 7. Fish Biol. 35, 275-286.

Emlen, S. T. \& Oring, L. W. 1977 Ecology, sexual selection and the evolution of mating systems. Science 197, 215-223.

FitzGerald, G. J., Guderley, H. \& Picard, P. 1989 Hidden reproductive costs in the three-spined stickleback (Gasterosteus aculeatus). Exp. Biol. 48, 295-300.

Frischknecht, M. 1993 The breeding coloration of male threespined sticklebacks (Gasterosteus aculeatus) as an indicator of energy investment in vigour. Evol. Ecol. 7, 439-450.

Getty, T. 1998 Handicap signalling: when fecundity and viability do not add up. Anim. Behav. 56, 127-130.

Guderley, H. 1994 Physiological ecology and evolution of the threespine stickleback. In The evolutionary biology of the threespine stickleback (ed. M. A. Bell \& S. A. Foster), pp. 85-113. Oxford University Press.

Hosking, M. G. 1996 The relationships among foraging success, sexual selection and life history in the threespine stickleback (Gasterosteus aculeatus). $\mathrm{PhD}$ dissertation, Indiana University, Bloomington, IN, USA.

Johnstone, R. A. \& Grafen, A. 1993 Dishonesty and the handicap principle. Anim. Behav. 46, 759-764.

Kokko, H. 1998 Should advertising parental care be honest? Proc. R. Soc. Lond. B 265, 1871-1878.

Lozano, G. A. 1994 Carotenoids, parasites, and sexual selection. Oikos 70, 309-311. 
McKinnon, J. S. 1995 Video mate preferences of female threespined sticklebacks from populations with divergent male coloration. Anim. Behar. 50, 1645-1655.

Milinski, M. \& Bakker, T. C. M. 1990 Female sticklebacks use male coloration in mate choice and hence avoid parasitized males. Nature 344, 330-333.

Moodie, G. E. E. 1972 Predation, natural selection and adaptation in an unusual threespine stickleback. Heredity 28, 155-167.

Polak, M. \& Starmer, W. T. 1998 Parasite-induced risk of mortality elevates reproductive effort in male Drosophila. Proc. R. Soc. Lond. B 265, 2197-2201.

Rohwer, S. 1978 Parent cannibalism of offspring and egg raiding as a courtship strategy. Am. Nat. 112, 429-440.

Sargent, R. C. 1992 Ecology of filial cannibalism in fish: theoretical perspectives. In Cannibalism: ecology and evolution among diverse taxa (ed. M. A. Elger \& B. J. Crespi), pp. 38-62. Oxford University Press.
Stanley, B. V. 1983 Effects of food supply on reproductive behaviour of male Gasterosteus aculeatus. $\mathrm{PhD}$ dissertation, University of Wales, Aberystwyth, UK.

Stanley, B. V. \& Wootton, R. J. 1986 Effects of ration and male density on the territoriality and nest-building of male threespined stickleback (Gasterosteus aculeatus). Anim. Behar. 34, 527-535.

Wedekind, G., Meyer, P., Frischknecht, M., Niggli, U. A. \& Pfander, H. 1998 Different carotenoids and potential information content of red coloration of male three-spined stickleback. 7. Chem. Ecol. 24, 787-801.

Whoriskey, F. G. \& FitzGerald, G. J. 1985 The effects of bird predation on an estuarine stickleback (Pisces: Gasterosteidae) community. Can. F. Zool. 63, 301-307.

Zahavi, A. 1975 Mate selection - a selection for a handicap. f. Theor. Biol. 53, 205-214.

Zar, J. H. 1996 Biostatistical analysis. London: Prentice-Hall International. 